\title{
Acknowledgment to Reviewers of Gastroenterology Insights in 2021
}

\author{
Gastroenterology Insights Editorial Office
}

Citation: Gastroenterology Insights Editorial Office. Acknowledgment to Reviewers of Gastroenterology Insights in 2021. Gastroenterol. Insights 2022, 13, 33-34. https:// doi.org/10.3390/gastroent13010005

Published: 26 January 2022

Publisher's Note: MDPI stays neutral with regard to jurisdictional claims in published maps and institutional affiliations.

Copyright: () 2022 by the author. Licensee MDPI, Basel, Switzerland. This article is an open access article distributed under the terms and conditions of the Creative Commons Attribution (CC BY) license (https://creativecommons.org/licenses/by/4.0/).

MDPI AG, St. Alban-Anlage 66, 4052 Basel, Switzerland

Rigorous peer-reviews are the basis of high-quality academic publishing. Thanks to the great efforts of our reviewers, Gastroenterology Insights was able to maintain its standards for the high quality of its published papers. Thanks to the contribution of our reviewers, in 2021, the median time to first decision was 18 days and the median time to publication was 43.5 days. The editors would like to extend their gratitude and recognition to the following reviewers for their precious time and dedication, regardless of whether the papers they reviewed were finally published:

Anand, Sachit

Antonioli, Luca

Aparicio Ugarriza, Raquel

Audrius, Dulskas

Baicus, Cristian

Barberio, Brigida

Benedek, Csilla

Candelli, Marcello

Cazacu, Irina

Chyau, Charng-Cherng

Dumic, Igor

Dutra, Samia V.

Emanuele, Sinagra

Faraci, Simona

Gardlik, Roman

Geisler, Anja

Ghadieh, Hilda E.

Gil, Krzysztof

Giogha, Cristina

Guerra, Iván

Guerrini, Susanna

Hai, Hoang

Hayashi, Kazunao

Heo, Jeong

Hong, Boohwi

Iwasaki, Sohshi

Jang, Tyng Yuan

Kaise, Mitsuru

Kawabata, Hideaki

Krawiec, Paulina

Kühl, Anja A.

Lhomme, Sébastien
Liang, Cher Wei

Liu, Chen-Hua

Lo, Chun-Han

Lombardo, Mauro

Lurje, Isabella

McCaughan, Geoffrey William

McCluskey, Stuart

Melstrom, Kurt A.

Midrio, Paola

Møller, Søren

Mora-López, Laura

Muciño, Jimena

Norvell, John

Noviello, Carmine

Ooi, Delicia Shu Qin

Ortenzi, Monica

Pascale, Marco Maria

Peixe, Paula

Pienar, Corina

Pink, Daniel

Poddighe, Dimitri

Pöling, Jochen

Pucci, Mairi

Rajapaksha, Indu G.

Rohani, Pejman

Rosolowska-Huszcz, Danuta

Scanu, Antonio Mario

Schaefer, Marion

Scott, Alasdair

Seth, Abhishek

Shah, Samir A

Shi, Jiajun 
Shibukawa, Goro

Sitarz, Robert

Solanki, Sumeet

Stasiowski, Michał Jan

Tsalikidis, Christos

Ursic-Bedoya, José

Uzunoglu, Faik G.
Verma, Alok K.

Wang, Bo

Wichmann, Doerte

Wilhelmi, Markus

Xaplanteri, Panagiota

Yen, Hsu-heng 